Western University

Scholarship@Western

$5-2015$

\title{
The Effects of Diet and the Microbiome on Reproduction and Longevity: A Comparative Review Across 5 Continents
}

Stephanie N. Chilton

Western University

Megan K. Enos

Western University, menos@uwo.ca

Jeremy P. Burton

Western University

Gregor Reid

Western University, gregor@uwo.ca

Follow this and additional works at: https://ir.lib.uwo.ca/mnipub

Part of the Immunology and Infectious Disease Commons, and the Microbiology Commons

Citation of this paper:

Chilton, Stephanie N.; Enos, Megan K.; Burton, Jeremy P.; and Reid, Gregor, "The Effects of Diet and the Microbiome on Reproduction and Longevity: A Comparative Review Across 5 Continents" (2015). Microbiology \& Immunology Publications. 45.

https://ir.lib.uwo.ca/mnipub/45 


\title{
The Effects of Diet and the Microbiome on Reproduction and Longevity: A Comparative Review Across 5 Continents
}

\author{
Stephanie N. Chilton ${ }^{1,2}$, Megan K. Enos ${ }^{1,3}$, Jeremy P. Burton ${ }^{1,2,3,4}$ and Gregor Reid ${ }^{1,2,3,4 *}$ \\ ${ }^{1}$ Canadian Centre for Human Microbiome and Probiotic Research, Lawson Health Research Institute, London, Canada \\ ${ }^{2}$ Physiology and Pharmacology, The University of Western Ontario, London, Canada \\ ${ }^{3}$ Microbiology and Immunology, The University of Western Ontario, London, Canada \\ ${ }^{4}$ Urology/Surgery, The University of Western Ontario, London, Canada
}

\begin{abstract}
Human longevity and quality of life remain key societal drivers, but the healthcare burden of diet-related chronic diseases is economically unmanageable. In recent years, it has been proposed that the composition and abundance profiles of certain bacterial phyla in the gut are indicators of malnutrition, and ill health. But, how much does the gut microbiome and diet really contribute to outcomes? The description of three microbial enterotypes remains to be verified, as does its significance for health tested across continents and within people who migrate from one lifestyle to another. It is not simply that the diet of one region causes a dominance of microbes not found in another, or that it leads to adverse outcomes. Venezuelans have a diet different from Americans, yet life expectancy and causes of death are somewhat similar. Pregnant east African women have very different diets to Europeans, yet excluding infectious disease exposure, successful reproduction occurs in both. The microbiome has added another layer of complexity to nutrition management, but with modern sequencing platforms and bioinformatics tools, integration of this information will soon be feasible. In providing dietary recommendations, especially during pregnancy, more consideration is needed on reducing exposure to environmental toxins, encouraging intake of fermented foods and those designed to improve fetal and infant development. By focusing on the first 1000 days of life, it may be possible to improve how we produce and allocate food, and provide a newborn with the best chance of leading a productive life.
\end{abstract}

Keywords: Microbiome; Longevity; Reproduction

\section{Introduction}

A new dimension has been added to the link between diet and health, namely the human gut microbiota, representing the largest collection of microbes inhabiting the human body [1]. Attempts have been made to categorize deviations from the norm that are associated with aberrant physiological outcomes, whether by changes in abundance of Phyla or Genera [2,3], or through elevated presence of certain organisms [4-6]. To date, there does not appear to be a universally 'normal' microbiota in the gut or at other sites; outliers have been reported in apparently healthy individuals where disease might have otherwise been expected [7]. The search for the perfect microbial profile seems futile, but uncovering a functionally 'normal' or healthy composition may be feasible considering the development of transcriptomic tools [8].

The composition of the human microbiome is multifactorial; given the impact of human genetics, method of birthing, early feeding, use of antimicrobials, and the living environment (home, people, air, water, food), it is no surprise that different microbial patterns exist $[9,10]$. Of particular interest is the influence of diet on the microbiota and how this relationship affects health and outcomes such as reproduction and longevity, the two most salient features of human survival. The aim of this review is to examine the current knowledge on this topic, and to provide our interpretation of its significance.

\section{Interaction between diet and the human gut microbiota}

Environmental factors are a major source of variation between individuals. Unrelated but cohabiting people have been shown to have more similar gut microbiotas to each other than to people from different households, likely from exposure to similar environments
[11] and diets. External factors such as infection [12], antibiotic use [13], sexual contact [14], exposure to environmental toxins [15] and even psychological stress [16] have been shown to cause shifts in the gut microbiota. For example, the negative impacts of antibiotic use on the microbiota are well known: an overall reduction in bacterial diversity, promotion of resistant species, and eradication of beneficial taxa, which creates room for pathogenic bacteria to grow, often occur [17]. Evidence suggests that in addition to short term damage, administration of antibiotics can have long-term consequences on the microbiota and overall health in both children [18] and adults [19]. Antibiotic use remains high, through people in developed countries having the financial resources, and those in developing countries often having access to cheap generic versions [20]. Thus, antibiotic use and lifestyle factors, such as sanitation, living conditions and diet, should be taken into account when examining gut microbiota composition.

In comparison, our understanding of dietary effects in relation to the microbiome is only now emerging. This has mostly been propagated

*Corresponding author: Gregor Reid, Canadian Centre for Human Microbiome and Probiotic Research, Lawson Health Research Institute, 268 Grosvenor St. N6A 4V2, London, Ontario, Canada, Tel: 519-646-6100 x 65256; Fax: 519-6466031; E-mail: gregor@uwo.ca

Received January 23, 2015; Accepted March 07, 2015; Published March 10 2015

Citation: Chilton SN, Enos MK, Burton JP, Reid G (2015) The Effects of Diet and the Microbiome on Reproduction and Longevity: A Comparative Review Across 5 Continents. J Nutr Food Sci 5: 364. doi:10.4172/2155-9600.1000364

Copyright: (c) 2015 Chilton SN, et al. This is an open-access article distributed under the terms of the Creative Commons Attribution License, which permits unrestricted use, distribution, and reproduction in any medium, provided the original author and source are credited. 
by the obesity epidemic and the ability to identify organisms by $16 \mathrm{~s}$ rRNA high throughput sequencing.

There are multiple known benefits that the gut microbiota confer on the host, including enhanced nutrient catabolism and absorption. Certain microbes within the gut aid in the breakdown of indigestible polysaccharides, such as cellulose and pectin, which would otherwise be excreted [21]. Fermentation of these carbohydrates by the microbiota produces short-chain fatty acids (SCFAs), which may be absorbed across the colonic epithelium into the blood stream. Some Firmicutes, including species from Faecalibacterium and Clostridium [22], as well as Bacteroidetes, specifically Prevotella [23], have been associated with this fermentative capacity. The energy production resulting from SCFAs produced by the gut microbiota can contribute an estimated $3-9 \%$ to the energy requirements of the human body [24].

In particular, the SCFA propionate can successfully enter anabolic pathways in the liver utilized for energy production-namely gluconeogenesis, lipogenesis and protein synthesis [25]. SCFAs can also be metabolized in peripheral tissues and become precursors for cholesterol synthesis [26]. As well, butyrate may be metabolized by colonic epithelium directly to account for most of this tissue's energy requirements [27]. Butyrate has been implicated in decreased risks of colorectal cancer and overall gastrointestinal health $[28,29]$. Fermentation of proteins by the gut microbiota, however, appears to produce toxic or carcinogenic molecules [30].

Further nutritional interactions with the gut microbiota include the metabolism of bile acids, whose major function lies in the emulsification and absorption of fatty material in the small intestine. Though the vast majority of bile acids are reabsorbed in the small intestine, a small percentage escapes into the large intestine and interacts with the microbiota. Here, the primary bile acids may be modified; bacteria enzymatically increase the hydrophobicity and allow the passive reabsorption of secondary bile acids across the colonic epithelium. The ability to modify primary bile acids has been associated with species of Lactobacillus, Bifidobacterium, Enterobacter, Bacteroides and Clostridium [31].

Secondary bile acids are then recycled to the liver for further processing and re-secretion, [32,33] contributing to fat, fat-soluble vitamin, and cholesterol absorption. Like carbohydrate and protein bacterial metabolites, secondary bile acids have been implicated in colorectal cancer. However, data suggest these molecules may be contributing to cancer formation [34], as opposed to the positive effects of carbohydrate metabolism and SCFA formation. Thus, it appears that a diet higher in indigestible carbohydrate (fiber), not proteins or fats, appears to offer a protective factor against cancer. Secondary bile acids have also been implicated to act as chemical messengers, affecting pathways involved in energy metabolism and intestinal homeostasis [35]. Other molecules secreted by the gut microbiota, such as choline metabolites and certain lipids, have been recognized as regulators of energy metabolism within the host [36].

Clearly the interactions of the gut microbiota with food and metabolism are multifold and complex. However, it is evident that a certain diet may be better digested and absorbed depending on the microbial community present in the gut. For a plant-based diet, microbes with fermentative capacity allow for more efficient harvest of energy through absorption of SCFAs. Likewise, a high-fat diet may be better absorbed or tolerated by the host through the presence of gut microbes able to withstand and modify primary bile acids (albeit while increasing the risk of colorectal cancer in the host). The ability of gut microbiota to aid the efficiency of nutrient extraction in their hosts may be beneficial in scenarios where the host is consuming a normal or nutrient-scarce diet. It is important to note however, that in individuals consuming more than what is required or in cases of aberrant gut microbiota compositions, these bacteria may contribute to weight gain and obesity.

\section{Effects of diets on the gut microbiota in five continents}

People in different parts of the world have developed nuances with respect to diet and lifestyles, influenced by climate, geographical factors, traditions and availability of foods. We will comment on countries from five continents where studies have investigated the human gut microbiota (Figure 1).

In developed countries of North America and Europe, where active trading occurs making foods widely available, the so-called "Western diet" prevails. High in protein, fat and refined grains, this diet includes processed red meat and sugary drinks and desserts, invariably sweetened with high-fructose corn syrup. In Japan, another developed country, the diet differs in that it generally contains higher amounts of rice, beans, fermented or pickled foods and fish. The effects of these "developed" diets on the gut microbiota appear to be increases in abundance of Firmicutes, as will be discussed in detail below.

A study published in 2011 by Arumugam et al. [23] tried to locate "enterotypes" of gut microbiomes amongst different populations. They combined 22 newly sequenced European (Danish, French, Italian and Spanish) microbiomes with those from Japan and The United States (US) from previous studies. Though inconsistent sequencing technologies were used across data sets, three distinguished "enterotypes" or clusters were found, which were mostly irrelevant to participant nationality (with the exception of Japanese-enriched enterotype 1) and driven by bacterial species composition. The three enterotypes were each dominated by a certain genus: Bacteroides, Prevotella and Ruminococcus. Notably, differences in nutrient metabolism and energy production existed between the three clusters. For example, certain Bacteroides have been reported to participate in carbohydrate and protein fermentation [37,38], while Prevotella species are known to degrade mucin [39], a glycoprotein.

Since all participants belonged to developed regions of the world, they likely had relatively similar exposure to environmental conditions

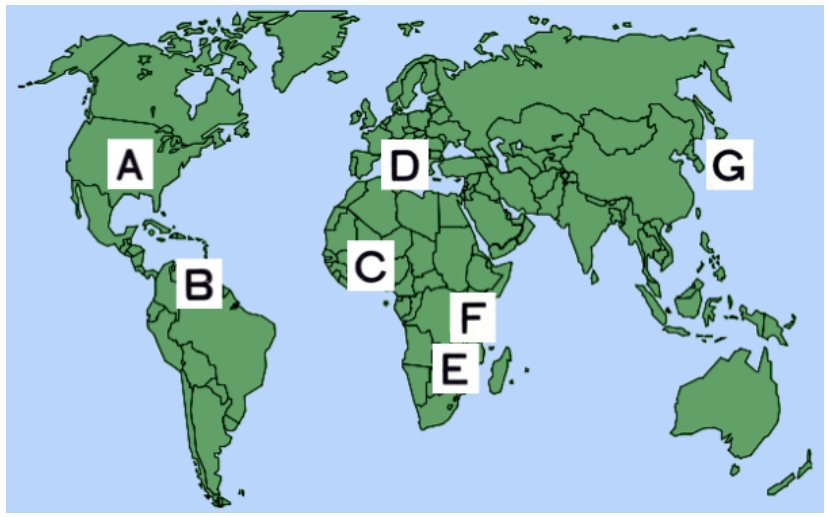

Figure 1: Global locations of microbiota studies. World map [37] of countries (A: The United States, B: Venezuela, C: Burkina Faso, D: Italy, E: Malawi, F: Tanzania, G: Japan) where scientists have reported gut microbiota compositions. 
such as sanitation and sufficient food. However, the typical Japanese diet differs slightly from the European or American, as mentioned earlier, potentially explaining the enrichment of Japanese participants in the Bacteroides cluster. A Bacteroides dominated gut, with the ability to ferment protein and carbohydrates [38], would be beneficial to a diet high in fish and rice, as consumed in Japan. Overall, it was concluded that enterotypes appear complex and any factor alone, including diet, is not enough to explain their presence [23].

Hehemann et al. [40] further elucidated differences between North American and Japanese individuals by finding saccharolytic enzymes in the gut microbiome of the latter. These enzymes, porphyranases and agarases, which were absent in North Americans, are responsible for the breakdown of sulphated polysaccharides present in seaweed, a food that makes up a significant portion of the Japanese diet but is consumed by North Americans in much lesser amounts [41]. The genes appear to have been transferred to the gut bacterium, Bacteroides pleibus, from Zobellia galactanivorans, a marine bacterium consumed with seaweed [40]. This finding suggested that continuous seaweed consumption led to emergence of microbes in the gut with the ability to break it down.

The aforementioned "Western diet" tends to be markedly different from diets in so-called developing countries (Burkina Faso (BF), Malawi and Venezuela are being considered as such), where refined and processed foods are much less available and high-fiber foods dominate. Data suggesting that a high-fiber diet favours a gut microbiota dominated by Bacteroidetes will be discussed. A comparison of diets based on macronutrient intake and dominant bacterial phylum is given below (Table 1). Of note, we will use the term «African» loosely, as clearly there are extreme differences between countries. In terms of dieticians providing advice to "Africans" spending time in, or emigrating to, Europe or North America, it is not known if and when their microbiota changes if they continue to consume a diet similar to the one they had in Africa, but it does appear that 'westernization' occurs and the microbiota alters in time, as will be explored below for Somali migrants to Canada.

Percent of total caloric intake (kcal) is influenced by macronutrient [42] and the reported dominant gut bacteria, according to phylum, for countries with characterized gut microbiotas, including the US [43].

A comparative study in 2010 by De Phillipo et al. [44] looked at children's diets and gut microbiotas from Italy and rural BF. All children were selected on the basis of age, physical growth and consumption of the typical diets associated with their nationalities. Differences in abundances of bacteria existed between the two populations; European children had greater proportions of Firmicutes and Proteobacteria, while Actinobacteria and Bacteroidetes were higher in the African children. In particular, Prevotella and Xylanibacter, both of which are capable of hydrolyzing plant polysaccharides [45], were more prevalent in BF microbiotas. In addition, in the BF children, microbial diversity was greater and SCFAs in feces were higher, as expected of a carbohydrate-

\begin{tabular}{|c|c|c|c|c|}
\hline \multirow{2}{*}{ Country } & \multicolumn{3}{|c|}{ Diet by Macronutrient } & \multirow{2}{*}{$\begin{array}{l}\text { Dominant } \\
\text { Bacteria }\end{array}$} \\
\hline & $\%$ Carb & $\%$ Protein & $\%$ Fat & \\
\hline Burkina Faso & 68 & 12 & 20 & Bacteroidetes \\
\hline Italy & 49 & 12 & 39 & Firmicutes \\
\hline Japan & 58 & 13 & 29 & Bacteroidetes \\
\hline Malawi & 77 & 10 & 13 & Bacteroidetes \\
\hline USA & 49 & 12 & 38 & Firmicutes \\
\hline Venezuela & 64 & 11 & 26 & Bacteroidetes \\
\hline
\end{tabular}

Table 1: Global macronutrient consumptions and gut microbiota compositions. enriched diet. These results indicate that the gut microbiota of children in $\mathrm{BF}$ has adapted well to their diet high in plant products. However, this study is limited by its sampling and lacks generalizability to the populations they were meant to represent; only 14 Italian and $15 \mathrm{BF}$ children were included and all children were under the age of 6 . Thus, a more comprehensive study including greater numbers of participants from various age groups and different countries could prove useful.

Yatsunenko et al. [11] filled in these gaps in the following year, where they consistently analyzed the gut microbiota of 531 individuals ranging in age from newborns to 70 year olds, from rural Malawi, Venezuela and urban areas of the US. The stool microbiota of children in all countries slowly evolved towards an adult microbiota during the first three years of life [11], suggesting that the maturation processes were the same, though the final composition was very dependent upon diet and environment. In support of this, microbiotas clustered according to US vs. non-US for both adults and children, with Prevotella significantly more represented in the latter, confirming the results of De Phillipo et al. [44] in BF. As well, US adults had the lowest intrapersonal variation in their microbiotas compared to non-US.

Furthermore, analysis of US, Malawian and Venezuelan adult microbiomes revealed differences clearly linked to diet [11]. In Americans, genes for enzymes involved in the following processes were significantly more represented: degradation of amino acids, catabolism of simple sugars, and metabolism of xenobiotics and bile salts reflecting a diet high in protein, fat and simple sugars. Conversely, in the non-US populations, amylases (required for starch breakdown) and enzymes involved in amino acid synthesis were more present, indicative of a diet high in carbohydrates and low in protein.

These results are interesting on many fronts. The US is a country that is large geographically with vast economical resources, plentiful food, state-of-the-art medical technology and care, and better longevity figures than Venezuela, BF and Malawi, yet the burden of healthcare spending on chronic conditions that are influenced by the microbiota is enormous, suggesting the US has far from the optimal diet and microbial profiles. It would seem that a vegetarian diet results in a gut microbiota dominated by Prevotella [46], and even transiently changing to a plant based diet may lower inflammatory processes [47]. Could this increased Prevotella abundance, which is known to cause oral malodour and associated with bacterial vaginosis $[48,49]$, actually be beneficial in the gut? If so, this suggests that the largely vegetarian staple diets in Malawi or Venezuela, compared to the American diet, may be promoting better health through their interactions with the gut microbiota. Noteably, Prevotella has also been implicated in children as a protective factor from diarrhea [50] and autism [51]. We recommend caution in how we portray trends in microbial abundances and communities, especially as the organisms in the stool are linked to the oral cavity and vagina. To some, a vegetarian diet might seem optimal, but it is a very complex issue and vegetarian nutrition itself has many dimensions [52].

In search of better understanding the link between dietary factors and the microbiome, Schnorr et al. [53] recently studied the Hadza hunter-gatherers of Tanzania. In comparison to an Italian control cohort, the Hadza had a greater proportion of Bacteroidetes, belonging to the genus Prevotella, and a lower representation of Firmicutes. Compared to BF children and Malawian individuals assessed in previous studies, Hadza were enriched in bacteria of Clostridiales, Ruminococcaceae and Blautia - potentially reflecting a response of the gut microbiota to the foraging lifestyle seen only with the Hadza. Nonetheless, these comparisons to BF children and Malawians are 
weakened by age differences among groups, considering age is a well-documented factor affecting the gut microbiota [54,55]. As well, clear differences in methodology between studies existed and may have impacted the results. For these reasons, caution is urged when interpreting the comparisons made in this study.

Still, within the Hadza themselves, differences were noted between the sexes, with women having higher proportions of Treponema while men were enriched in Eubacterium and Blautia. Since women are known to forage for and consume more plant-based food while men consume more meat and honey, these differences appear to reflect lifestyle, particularly small shifts in the diet. Further studies of the Hadza are ongoing, hopefully teasing apart the subtleties of dietary intake, microbiota changes and health outcomes, especially in people never exposed to 'modern medicine', drugs and vaccination.

Another fairly unique cohort are the Hutterites, a secluded communal population living along the west coast of Canada and the US, who are characterized by low genetic variation but have access to modern technology and health care. The Hutterites have a stable diet throughout the year, except during summer when fresh produce is consumed [56]. The gut microbiotas of 60 Hutterite participants were sampled during the winter and summer months of one year to compare microbial composition between the seasons. For both common (Bacteroidetes, Firmicutes and Actinobacteria) and rare (Chloroflexi and Gemmatimonadetes) bacteria, shifts in abundance were noted across all taxonomic groups. For example, Bacteroidetes increased and Actinobacteria decreased during the summer months, presumably resulting in higher levels of enzymes required to digest polysaccharides in fresh produce. Winter months gave rise to gut microbiotas with greater biodiversity than in summer. Note that while these dietary recalls are useful, they do not account for influences such as pathogenic exposure [57] and daylight duration [58], both of which change with the seasons and can affect gut microbiota (Table 1).

A study of Native Africans and African Americans not only showed the genus Prevotella was higher in the former and Bacteroides more prevalent in the latter, but also showed higher diversity in the Americans supposedly because of a more diversified diet [59]. Although this study did not imply a more diverse microbiota is 'preferable' in terms of health, others have certainly implied this through association [6062]. Such conclusions, regardless of the different tools used to acquire the data, should also be treated with caution. Likewise, conclusions based exclusively on rodent studies irrespective of the mechanisms of microbial action they might uncover [63-65], need to be taken for what they are - studies in rodents. Of more pertinence to humans are studies performed in humans. Thus for the vagina, a lower bacterial diversity dominated by lactobacilli is clearly associated with health [66], and is irrespective of the diversity of the gut microbiota which has access to the vagina via the rectum and perineum. Thus, high bacterial diversity should not be seen as a definitive marker for health or disease.

\section{Impacts of long-term diet and the gut microbiota on longevity}

There exists a major discord in longevity and causes of death across the globe. In the developed world, life expectancy is high and death frequently occurs from non-communicable diseases in elderly life. In comparison, populations from the developing world die much younger and often from infectious diseases or conditions such as malnutrition (Tables 2 and 3). Tables are based upon average life expectancies and major causes of death [67], as of 2011, for developed countries where gut microbiotas have been characterized.

The overlap between developed countries is significant; stroke,

\begin{tabular}{|c|c|c|c|}
\hline & Japan & Italy & USA \\
\hline $\begin{array}{l}\text { Average life } \\
\text { expectancy }\end{array}$ & 82.7 & 82.4 & 78.6 \\
\hline \multirow{5}{*}{$\begin{array}{l}\text { Top } 5 \text { causes of } \\
\text { death }\end{array}$} & 1. Stroke & $\begin{array}{l}\text { 1. Coronary Heart } \\
\text { Disease }\end{array}$ & $\begin{array}{l}\text { 1. Coronary Heart } \\
\text { Disease }\end{array}$ \\
\hline & $\begin{array}{l}\text { 2. Influenza and } \\
\text { Pneumonia }\end{array}$ & 2. Stroke & $\begin{array}{l}\text { 2. Alzheimer's/ } \\
\text { Dementia }\end{array}$ \\
\hline & $\begin{array}{l}\text { 3. Coronary Heart } \\
\text { Disease }\end{array}$ & 3. Lung Cancer & 3. Lung Cancer \\
\hline & 4. Lung Cancer & 4. Hypertension & 4. Stroke \\
\hline & 5. Stomach Cancer & 5. Lung Disease & 5. Lung Disease \\
\hline
\end{tabular}

Table 2: Longevity data of developed countries.

\begin{tabular}{|c|c|c|c|}
\hline & Venezuela & Malawi & Burkina Faso \\
\hline $\begin{array}{l}\text { Average Life } \\
\text { Expectancy }\end{array}$ & 75.5 & 57.7 & 55.8 \\
\hline \multirow{5}{*}{$\begin{array}{l}\text { Top } 5 \text { Causes of } \\
\text { Death }\end{array}$} & $\begin{array}{l}\text { 1. Coronary } \\
\text { Heart Disease }\end{array}$ & 1. HIVIAIDS & 1. Malaria \\
\hline & 2. Violence & $\begin{array}{l}\text { 2. Influenza and } \\
\text { Pneumonia }\end{array}$ & $\begin{array}{l}\text { 2. Influenza and } \\
\text { Pneumonia }\end{array}$ \\
\hline & 3. Stroke & 3. Diarrheal Diseases & $\begin{array}{l}\text { 3. Diarrheal } \\
\text { Diseases }\end{array}$ \\
\hline & $\begin{array}{l}\text { 4.Road Traffic } \\
\text { Accidents }\end{array}$ & 4. Malaria & 4. HIVIAIDS \\
\hline & $\begin{array}{l}\text { 5. Diabetes } \\
\text { Mellitus }\end{array}$ & 5. Stroke & 5. Tuberculosis \\
\hline
\end{tabular}

Table 3: Longevity data of developing countries.

coronary heart disease and lung cancer represent three out of the five leading causes of death in each (Table 2). Lifestyle factors such as diets high in fat and cholesterol, inactivity, obesity, smoking and alcohol use, are all major contributors to one or more of these conditions.

In contrast, similarities between the three developing countries of interest are much less unanimous (Table 3). Venezuela, in particular, stands apart from the others in that Venezuelans appear to be dying from diseases commonly seen in the developed world, such as coronary heart disease, stroke and diabetes. Meanwhile, the two African countries, Malawi and Burkina Faso, have similar causes of death: HIV/AIDS, influenza and pneumonia, diarrhoeal diseases and malaria. Of note, disruptions to the gut microbiota have been associated with diarrhea [68,69], specifically, decreases to Eubacterium rectale, species of Bacteroides and Faecalibacterium prausnitzii have been reported.

A Venezuelan diet is very similar in macronutrient composition to $\mathrm{BF}$ and Malawi diets in that they are all dominated by carbohydrates. The gut appears to have responded with an increased prevalence of Bacteroidetes, in comparison to developed nations. However, Venezuelans are living much longer (approximately 20 years on average) than people from BF and Malawi, and are actually closer in average life expectancy to the US. Thus, a Venezuelan diet resembles that of the developing countries, yet their longevity mimics that of a developed country. Clearly other factors, whose effects do not manifest through the diet or the gut microbiota, must be involved in influencing longevity. Availability of necessary resources and access to medical care are major differences between the low and high-income countries, and these clearly can affect longevity.

A growing number of studies have linked gut microbiome dysbiosis composition to disease and pathology, such as colorectal cancer [70], obesity [71] and diabetes [72]. Recent evidence suggests that interactions between the gut microbiota and the brain also exist and neural conditions such as multiple sclerosis [73], autism, anxiety 
and depression, may be modulated by the intestinal microbes [74]. All these conditions shorten longevity.

The aforementioned results of Yatsunenko et al. [11] are also interesting in that all three cultures examined (Venezuela, Malawi and US) had similar trends with the progression of their gut microbiotas over time. In all three populations, children evolved towards an adult-like composition by three years of age. Furthermore, as the subjects aged into adulthood, all were characterised by a decrease in interpersonal variation yet an increase in intra-individual diversity. These consistencies suggest that the pattern of microbiota progression throughout one's lifetime is independent of geography and that the microbiota is tightly linked with age, and perhaps longevity. This would be quite remarkable in terms of human evolution given the diverse conditions of how the continents separated through time.

Other data exist that further suggest a link between the gut microbiota and longevity. A study conducted on elderly people found correlations between both food and gut microbiota composition to indicators of health, such as frailty, nutritional status and comorbidity [75]. Thus, throughout one's lifetime and well into old age, the gut microbiota composition still plays a role in overall health and helps determine longevity.

Ultimately, we must not underestimate the impacts of diet on longevity; in any part of the world, a high calorie diet coupled with a sedentary lifestyle is a predictor of obesity and life-threatening conditions such as coronary heart disease, diabetes or cancer.

\section{How does the maternal diet and microbiome affect reproduction?}

During pregnancy, large changes to microbial composition of the maternal gut have been reported. Levels of Proteobacteria and Actinobacteria appear to increase while overall richness decreases between the first and third trimester [76,77]. Interestingly, one study showed that while diets of women went mostly unchanged throughout pregnancy, major changes to the gut microbiota still occurred [78]. This finding dilutes the argument that diet alters the gut microbiota during pregnancy, instead suggesting hormonally or immunologicallydriven changes in the gut.

To examine this more closely, we studied the gut microbiota and response to nutrient-enriched probiotic yogurt in undernourished, healthy and obese pregnant women in Tanzania. Five groups comprised: undernourished (UN), undernourished given probiotic (UNP), nourished $(\mathrm{N})$, nourished given probiotic $(\mathrm{NP})$ and obese $(\mathrm{O})$. Diets of all women were carefully recorded 48 hours prior to each visit in dietary recall surveys (Figure 2). Administration of the probiotic did not have a significant impact on the maternal gut microbiota, however the microbiotas of babies born to these mothers were significantly affected [78].

Of note, no significant differences in micro- or macronutrient consumption between groups were detected at the first visit. However, as the study continued, calcium levels in the probiotic groups (NP and UNP) were higher than all others. In comparison to reference dietary intake (RDI) values for Canadian pregnant women, the Tanzanian women only met requirements for carbohydrates and iron throughout pregnancy - all other micronutrients were below 90\% of the RDI, including folate. Yet, incidence of premature birth, infant mortality and low birth weights were low and overall, babies appeared to be healthy [78].
The intriguing point from this study is that the gut microbiota profiles were not directly related to the nutritional status of the mother or to pregnancy outcome. Admittedly, the levels of malnutrition were not extreme, and clearly very low-calorie maternal diets in early and mid-gestation have severe long-term effects on the baby, such as diabetes, obesity and cardiovascular disease $[79,80]$. Indeed, it may be assumed that folate levels of the mother were sufficiently high to prevent neural tube defects in the baby. We did however find that infant oral and fecal microbiotas were associated with the maternal breast milk microbiota. Thus, this suggests a mechanism, outside the maternal gut, by which the mother could be passing on her nutrition and health status to her child, albeit in the long-term. In relation to this, there is strong evidence for a link between early microbiota composition and later appearance of childhood disease [81]. But, as we have argued, the type of diet consumed and the composition of maternal microbiota seem somewhat unimportant in predicting immediate pregnancy outcomes.

There are very limited dietary guidelines for conception, apart from avoidance of alcohol, caffeine, artificial sweeteners, recreational drugs, cigarettes, vitamin A and liver products. The US Public Health Service and British Nutrition Foundation recommend that women of childbearing age obtain 400 micrograms $(\mathrm{mg})$ of folate or folic acid each day, and $1000 \mathrm{mg}$ calcium. Some organizations also recommend $15 \mathrm{mg}$ a day of zinc to support ovulation and fertility. In men, selenium is recommended to support semen and testosterone production. Notably, increased consumption of fermented foods is recommended on many online resources, mostly for their ability to aid in digestion and nutrient uptake. To date, the potential importance of lactobacilli from fermented foods, being a source of alpha-linoleic acid or helping

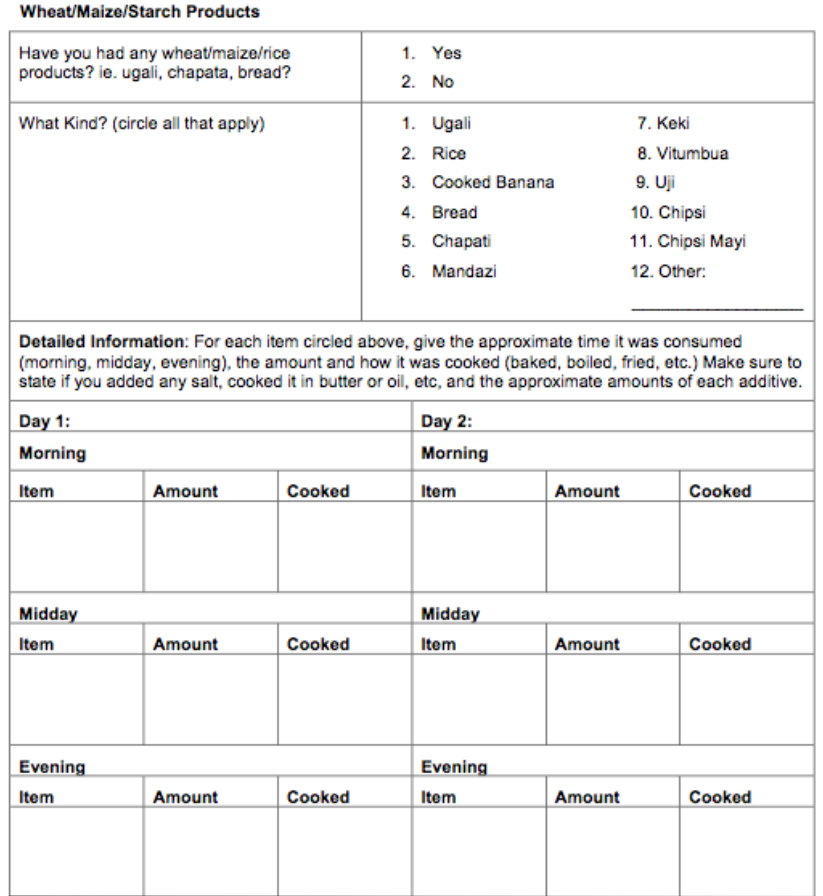

Figure 2: Dietary recall format, completed Wheat/Maize/Starch Products section of the dietary recall. Additional types of food surveyed include roots and tubers, fruits, vegetables, meat, fish, eggs, beans and milk products. Sugar products, beverages and salt intake were also recorded. For each section, the type of food, amount, time (breakfast, lunch or dinner) and method of cooking were recorded. 
to improve vaginal health, have not been widely considered as part of dietary recommendations for pregnancy [82]. Given the importance of the former in neural development [83] and the latter in potentially countering bacterial vaginosis and preterm birth [84], further studies are merited. The lactobacilli may also be beneficial to counter environmental toxins [85], which some naturopaths encourage avoidance of by consuming of fresh, organically grown food [86]. Toxins, such as mercury and organochlorine pesticides, are known to adversely affect pregnancy and infant outcomes including birth size, reflexes, attention, alertness and performance impairment [87-91]. Guidelines are needed for pregnancy given the widespread presence of these compounds in developed and developing countries [92,93].

It seems prudent that we do not jump to conclude that one diet is more healthy than another. In the 1970s, MacDonald's promoted 'cheap, quick and tasty' foods that resulted in countries around the world seeking out the fast food chains and eating out more than at home [94]. Ironically, the sought-after 'Western' diet has now expanded to many developing countries and is changing the profile of diseases causing death. This is a form of 'nutrition transition' first described in 1902 at a Missionary hospital in Labrador, Canada, where doctors could not find any cancer, asthma, appendicitis or other "European" diseases amongst the Eskimo, who were meat eaters with practically no vegetables in their diet. But, they witnessed a 'nutrition transition' to westernized food that was followed by significant increases in cancer rates [95].

In Africa today, younger generations are attracted to fast, poorlynutritious lifestyle foods, rather than traditional, home-made, fermented foods [96]. Presumably, the microbiota of the gut will transition accordingly, but perhaps not fast or effectively enough, as seems to be the case for Somali immigrants to the developing world, where their newborns are experiencing high rates of autism [97]. It remains to be determined if such diseases are caused by how microbes adapt to the dietary changes.

It should be remembered that despite vastly different diets, women around the world continue to give birth to healthy babies, as far as can be determined. There is clearly a knowledge gap for maternal genetics, diet and microbiota and health of the fetus and growing child. By focusing on the first 1000 or so days of life, it may be possible to improve how we produce and allocate food, and provide a newborn with the best chance of leading a long and productive life [98]. The diverse nature of many societies requires a re-examination of national food guides to better link microbiota profiles with diet, since this is potentially a better predictor of diseases [99]. Furthermore, longevity figures and disease profiles for developed and developing countries do not necessarily reflect diet and gut microbial composition, exemplified by Venezuela. As such, we hypothesize that microbes can play a major role in reproduction and overall health, but it is how they function irrespective of diet, rather than their diversity and composition, that is most important.

In an emerging global society, with foods traveling across continents so that the developed world may eat what they want when they want, we must study more intensely the impact this has on the human microbiome, and how these microbes interact with the foods and human host. Developing countries, such as Malawi and BF, may well be an example where a core diet exists that is sufficient for reproduction and survival of the human species. Understanding this and supplementing newborns with specific foods that decrease the risk of malnutrition could help humankind better balance the food supply needed in the future.

\section{References}

1. Clemente JC, Ursell LK, Parfrey LW, Knight R (2012) The impact of the gut microbiota on human health: an integrative view. Cell 148: 1258-1270.

2. Frank DN, St Amand AL, Feldman RA, Boedeker EC, Harpaz N, et al. (2007) Molecular-phylogenetic characterization of microbial community imbalances in human inflammatory bowel diseases. Proc Natl Acad Sci U S A 104: 1378013785.

3. Lepage P, Häsler R, Spehlmann ME, Rehman A, Zvirbliene A, et al. (2011) Twin study indicates loss of interaction between microbiota and mucosa of patients with ulcerative colitis. Gastroenterology 141: 227-236.

4. Rowan F, Docherty NG, Murphy M, Murphy B, Calvin Coffey J, et al. (2010) Desulfovibrio bacterial species are increased in ulcerative colitis. Dis Colon Rectum 53: 1530-1536.

5. Ohkusa T, Sato N, Ogihara T, Morita K, Ogawa M, et al. (2002) Fusobacterium varium localized in the colonic mucosa of patients with ulcerative colitis stimulates species-specific antibody. J Gastroenterol Hepatol 17: 849-853.

6. Sokol H, Lepage P, Seksik P, Doré J, Marteau P (2006) Temperature gradient gel electrophoresis of fecal 16S rRNA reveals active Escherichia coli in the microbiota of patients with ulcerative colitis. J Clin Microbiol 44: 3172-3177.

7. Kim TK, Thomas SM, Ho M, Sharma S, Reich Cl, et al. (2009) Heterogeneity of vaginal microbial communities within individuals. J Clin Microbiol 47: 11811189.

8. Macklaim JM, Fernandes AD, Di Bella JM, Hammond JA, Reid G, et al (2013) Comparative meta-RNA-seq of the vaginal microbiota and differentia expression by Lactobacillus iners in health and dysbiosis. Microbiome 1: 12 .

9. Penders J, Thijs C, Vink C, Stelma FF, Snijders B, et al. (2006) Factors influencing the composition of the intestinal microbiota in early infancy. Pediatrics 118: 511-521.

10. Azad MB, Konya T, Maughan H, Guttman DS, Field CJ, et al. (2013) Gut microbiota of healthy Canadian infants: profiles by mode of delivery and infant diet at 4 months. CMAJ 185: 385-394.

11. Yatsunenko T, Rey FE, Manary MJ, Trehan I, Dominguez-Bello MG, et al. (2012) Human gut microbiome viewed across age and geography. Nature 486 222-227.

12. Belzer C, Gerber GK, Roeselers G, Delaney M, DuBois A, et al. (2014) Dynamics of the microbiota in response to host infection. PLoS One 9: e95534.

13. Dethlefsen L, Relman DA (2011) Incomplete recovery and individualized responses of the human distal gut microbiota to repeated antibiotic perturbation. Proc Natl Acad Sci U S A 108 Suppl 1: 4554-4561.

14. Borovkova N, Korrovits $P$, Ausmees K, Türk S, Jõers K, et al. (2011) Influence of sexual intercourse on genital tract microbiota in infertile couples. Anaerobe 17: $414-418$.

15. Smith LE, Stoltzfus RJ, Prendergast A (2012) Food chain mycotoxin exposure gut health, and impaired growth: a conceptual framework. Adv Nutr 3: 526-531.

16. Bailey MT, Dowd SE, Galley JD, Hufnagle AR, Allen RG, et al. (2011) Exposure to a social stressor alters the structure of the intestinal microbiota: implications for stressor-induced immunomodulation. Brain Behav Immun 25: 397-407.

17. Modi SR, Collins JJ, Relman DA (2014) Antibiotics and the gut microbiota. J Clin Invest 124: 4212-4218.

18. Munyaka PM, Khafipour E, Ghia JE (2014) External influence of early childhood establishment of gut microbiota and subsequent health implications. Front Pediatr 2: 109.

19. Jernberg C, Löfmark S, Edlund C, Jansson JK (2007) Long-term ecological impacts of antibiotic administration on the human intestinal microbiota. ISME J 1: $56-66$.

20. Van Boeckel TP, Gandra S, Ashok A, Caudron Q, Grenfell BT, et al (2014) Global antibiotic consumption 2000 to 2010: an analysis of national pharmaceutical sales data. Lancet Infect Dis 14: 742-750.

21. Bäckhed F, Ley RE, Sonnenburg JL, Peterson DA, Gordon JI (2005) Hostbacterial mutualism in the human intestine. Science 307: 1915-1920.

22. Louis P, Flint HJ (2009) Diversity, metabolism and microbial ecology of butyrate-producing bacteria from the human large intestine. FEMS Microbio Lett 294: 1-8. 
Citation: Chilton SN, Enos MK, Burton JP, Reid G (2015) The Effects of Diet and the Microbiome on Reproduction and Longevity: A Comparative Review Across 5 Continents. J Nutr Food Sci 5: 364. doi:10.4172/2155-9600.1000364

23. Arumugam M, Raes J, Pelletier E, Le Paslier D, Yamada T, et al. (2011) Enterotypes of the human gut microbiome. Nature 473: 174-180.

24. Wilson M (2005) Microbial Inhabitants of Humans. Cambridge University Press, Cambridge, UK.

25. Wolever TM, Spadafora $\mathrm{P}$, Eshuis $\mathrm{H}$ (1991) Interaction between colonic acetate and propionate in humans. Am J Clin Nutr 53: 681-687.

26. Wolever TM, Brighenti F, Royall D, Jenkins AL, Jenkins DJ (1989) Effect of rectal infusion of short chain fatty acids in human subjects. Am J Gastroenterol 84: 1027-1033.

27. Scheppach W (1994) Effects of short chain fatty acids on gut morphology and function. Gut 35: S35-38.

28. McIntyre A, Gibson PR, Young GP (1993) Butyrate production from dietary fibre and protection against large bowel cancer in a rat model. Gut 34: 386-391.

29. Fung KY, Cosgrove L, Lockett T, Head R, Topping DL (2012) A review of the potential mechanisms for the lowering of colorectal oncogenesis by butyrate. Br J Nutr 108: 820-831.

30. Guarner F, Malagelada JR (2003) Gut flora in health and disease. Lancet 361 512-519.

31. Ridlon JM, Kang DJ, Hylemon PB (2006) Bile salt biotransformations by human intestinal bacteria. J Lipid Res 47: 241-259.

32. Russell DW (2003) The enzymes, regulation, and genetics of bile acid synthesis. Annu Rev Biochem 72: 137-174.

33. Chiang JY (2009) Bile acids: regulation of synthesis. J Lipid Res 50: 19551966.

34. Louis P, Hold GL, Flint HJ (2014) The gut microbiota, bacterial metabolites and colorectal cancer. Nat Rev Microbiol 12: 661-672.

35. Vavassori P, Mencarelli A, Renga B, Distrutti E, Fiorucci S (2009) The bile acid receptor FXR is a modulator of intestinal innate immunity. J Immunol 183 6251-6261.

36. Nicholson JK, Holmes E, Kinross J, Burcelin R, Gibson G, et al. (2012) Host-gut microbiota metabolic interactions. Science 336: 1262-1267.

37. Free world maps (2014) Green-blue political world map A2.

38. Martens EC, Koropatkin NM, Smith TJ, Gordon JI (2009) Complex glycan catabolism by the human gut microbiota: the Bacteroidetes Sus-like paradigm. J Biol Chem 284: 24673-24677.

39. Wright DP, Rosendale DI, Robertson AM (2000) Prevotella enzymes involved in mucin oligosaccharide degradation and evidence for a small operon of genes expressed during growth on mucin. FEMS Microbiol Lett 190: 73-79.

40. Hehemann JH, Correc G, Barbeyron T, Helbert W, Czjzek M, et al. (2010) Transfer of carbohydrate-active enzymes from marine bacteria to Japanese gut microbiota. Nature 464: 908-912.

41. Fukuda S, Saito H, Nakaji S, Yamada M, Ebine N, et al. (2007) Pattern of dietary fiber intake among the Japanese general population. Eur J Clin Nutr 61: 99-103.

42. ChartsBin (2011) Dietary Macronutrient Composition per capita

43. American Gut (2013) Preliminary characterization of the American gut population.

44. De Filippo C, Cavalieri D, Di Paola M, Ramazzotti M, Poullet JB, et al. (2010) Impact of diet in shaping gut microbiota revealed by a comparative study in children from Europe and rural Africa. Proc Natl Acad Sci U S A 107: 1469114696.

45. Flint HJ, Bayer EA, Rincon MT, Lamed R, White BA (2008) Polysaccharide utilization by gut bacteria: potential for new insights from genomic analysis. Nat Rev Microbiol 6: 121-131.

46. Ruengsomwong S, Korenori Y, Sakamoto N, Wannissorn B, Nakayama J, et al. (2014) Senior Thai fecal microbiota comparison between vegetarians and non-vegetarians using PCR-DGGE and real-time PCR. J Microbiol Biotechno 24: 1026-1033

47. David LA, Maurice CF, Carmody RN, Gootenberg DB, Button JE, et al. (2014) Diet rapidly and reproducibly alters the human gut microbiome. Nature 505 : 559-563.
48. Yang F, Huang S, He T, Catrenich C, Teng F, et al. (2013) Microbial basis of oral malodor development in humans. J Dent Res 92: 1106-1112.

49. Pépin J, Deslandes S, Giroux G, Sobéla F, Khonde N, et al. (2011) The complex vaginal flora of West African women with bacterial vaginosis. PLoS One 6: e25082.

50. Pop M, Walker AW, Paulson J, Lindsay B, Antonio M, et al. (2014) Diarrhea in young children from low-income countries leads to large-scale alterations in intestinal microbiota composition. Genome Biol 15: R76.

51. Kang DW, Park JG, Ilhan ZE, Wallstrom G, Labaer J, et al. (2013) Reduced incidence of Prevotella and other fermenters in intestinal microflora of autistic children. PLoS One 8: e68322.

52. Metz M, Hoffmann I (2010) Effects of vegetarian nutrition-A nutrition ecologica perspective. Nutrients 2: 496-504.

53. Schnorr SL, Candela M, Rampelli S, Centanni M, Consolandi C, et al. (2014) Gut microbiome of the Hadza hunter-gatherers. Nat Commun 5: 3654.

54. Biagi E, Nylund L, Candela M, Ostan R, Bucci L, et al. (2010) Through ageing, and beyond: gut microbiota and inflammatory status in seniors and centenarians. PLoS One 5: e10667.

55. Salazar N, Arboleya S, Valdés L, Stanton C, Ross P, et al. (2014) The human intestinal microbiome at extreme ages of life. Dietary intervention as a way to counteract alterations. Front Genet 5:406.

56. Davenport ER, Mizrahi-Man O, Michelini K, Barreiro LB, Ober C, et al. (2014) Seasonal variation in human gut microbiome composition. PLoS One 9 : e90731.

57. Dowell SF (2001) Seasonal variation in host susceptibility and cycles of certain infectious diseases. Emerg Infect Dis 7: 369-374.

58. Bailey MT, Walton JC, Dowd SE, Weil ZM, Nelson RJ (2010) Photoperiod modulates gut bacteria composition in male Siberian hamsters (Phodopus sungorus). Brain Behav Immun 24: 577-584.

59. Ou J, Carbonero F, Zoetendal EG, DeLany JP, Wang M, et al. (2013) Diet, microbiota, and microbial metabolites in colon cancer risk in rural Africans and African Americans. Am J Clin Nutr 98: 111-120.

60. Ahn J, Sinha R, Pei Z, Dominianni C, Wu J, et al. (2013) Human gut microbiome and risk for colorectal cancer. J Natl Cancer Inst 105: 1907-1911.

61. Turnbaugh PJ, Ridaura VK, Faith JJ, Rey FE, Knight R, et al. (2009) The effect of diet on the human gut microbiome: a metagenomic analysis in humanized gnotobiotic mice. Sci Transl Med 1: 6ra14.

62. Sha S, Xu B, Wang X, Zhang Y, Wang H, et al. (2013) The biodiversity and composition of the dominant fecal microbiota in patients with inflammatory bowel disease. Diagn Microbiol Infect Dis 75: 245-251.

63. Hsiao EY, McBride SW, Hsien S, Sharon G, Hyde ER, et al. (2013) Microbiota modulate behavioral and physiological abnormalities associated with neurodevelopmental disorders. Cell 155: 1451-1463.

64. Veiga P, Gallini CA, Beal C, Michaud M, Delaney ML, etal. (2010) Bifidobacterium animalis subsp. lactis fermented milk product reduces inflammation by altering a niche for colitogenic microbes. Proc Natl Acad Sci U S A 107: 18132-18137.

65. Park AJ, Collins J, Blennerhassett PA, Ghia JE, Verdu EF, et al. (2013) Altered colonic function and microbiota profile in a mouse model of chronic depression. Neurogastroenterol Motil 25: 733-e575.

66. Gajer P, Brotman RM, Bai G, Sakamoto J, Schutte UM, et al. (2012) Tempora dynamics of the human vaginal microbiota. Sci Transl Med 4: 132ra52.

67. LeDuc Media. (2011) World Health Rankings.

68. Swidsinski A, Loening-Baucke V, Verstraelen H, Osowska S, Doerffel Y (2008) Biostructure of fecal microbiota in healthy subjects and patients with chronic idiopathic diarrhea. Gastroenterology 135: 568-579.

69. Gareau MG, Sherman PM, Walker WA (2010) Probiotics and the gut microbiota in intestinal health and disease. Nat Rev Gastroenterol Hepatol 7: 503-514.

70. Gao Z, Guo B, Gao R, Zhu Q, Qin H (2015) Microbiota disbiosis is associated with colorectal cancer. Front Microbiol 6: 20

71. Tsai F, Coyle WJ (2009) The microbiome and obesity: is obesity linked to our gut flora? Curr Gastroenterol Rep 11: 307-313.

72. Wen L, Ley RE, Volchkov PY, Stranges PB, Avanesyan L, et al. (2008) Innate 
Citation: Chilton SN, Enos MK, Burton JP, Reid G (2015) The Effects of Diet and the Microbiome on Reproduction and Longevity: A Comparative Review Across 5 Continents. J Nutr Food Sci 5: 364. doi:10.4172/2155-9600.1000364

immunity and intestinal microbiota in the development of Type 1 diabetes. Nature 455: 1109-1113

73. Bhargava P, Mowry EM (2014) Gut microbiome and multiple sclerosis. Curr Neurol Neurosci Rep 14: 492

74. Mayer EA, Knight R, Mazmanian SK, Cryan JF, Tillisch K (2014) Gut microbes and the brain: paradigm shift in neuroscience. J Neurosci 34: 15490-15496.

75. Claesson MJ, Jeffery IB, Conde S, Power SE, O'Connor EM, et al. (2012) Gut microbiota composition correlates with diet and health in the elderly. Nature 488: 178-184.

76. Collado MC, Isolauri E, Laitinen K, Salminen S (2008) Distinct composition of gut microbiota during pregnancy in overweight and normal-weight women. Am J Clin Nutr 88: 894-899.

77. Koren O, Goodrich JK, Cullender TC, Spor A, Laitinen K, et al. (2012) Host remodeling of the gut microbiome and metabolic changes during pregnancy. Cell 150: 470-480.

78. Enos MK (2014) The effect of nutrition on the microbiome in pregnant women and the use of micronutrient supplemented probiotic yogurt to improve outcomes. PhD Thesis, Western University, Canada.

79. Roseboom T, de Rooij S, Painter R (2006) The Dutch famine and its long-term consequences for adult health. Early Hum Dev 82: 485-491.

80. Janssen $\mathrm{Cl}$, Kiliaan AJ (2014) Long-chain polyunsaturated fatty acids (LCPUFA) from genesis to senescence: the influence of LCPUFA on neural development, aging, and neurodegeneration. Prog Lipid Res 53: 1-17.

81. Munyaka PM, Khafipour E, Ghia JE (2014) External influence of early childhood establishment of gut microbiota and subsequent health implications. Front Pediatr 2: 109

82. Chilton SN, Burton JP, Reid G (2015) Inclusion of fermented foods in food guides around the world. Nutrients 7: 390-404

83. Jurewicz J, Polaska K, Hanke W (2013) Chemical exposure early in life and the neurodevelopment of children--an overview of current epidemiological evidence. Ann Agric Environ Med 20: 465-486.

84. Reid G (2014) Modulating the vaginal microbiome: the need for a bridge between science and practice. Semin Reprod Med 32: 28-34

85. Monachese M, Burton JP, Reid G (2012) Bioremediation and tolerance of humans to heavy metals through microbial processes: a potential role for probiotics? Appl Environ Microbiol 78: 6397-6404.

86. Taylor CM, Golding J, Emond AM (2014) Lead, cadmium and mercury levels in pregnancy: the need for international consensus on levels of concern. J Dev Orig Health Dis 5: 16-30

87. Chehimi L, Roy V, Jeljeli M, Sakly M (2012) Chronic exposure to mercuric chloride during gestation affects sensorimotor development and later behaviour in rats. Behav Brain Res 234: 43-50.

88. Zhang Y, Bolivar VJ, Lawrence DA (2013) Maternal exposure to mercury chloride during pregnancy and lactation affects the immunity and socia behavior of offspring. Toxicol Sci 133: 101-111.

89. Al-Saleh I, Al-Rouqi R, Obsum CA, Shinwari N, Mashhour A, et al. (2014) Mercury $(\mathrm{Hg})$ and oxidative stress status in healthy mothers and its effect on birth anthropometric measures. Int J Hyg Environ Health 217: 567-585.

90. Chand S, Mustafa MD, Banerjee BD, Guleria K (2014) CYP17A1 gene polymorphisms and environmental exposure to organochlorine pesticides contribute to the risk of small for gestational age. Eur J Obstet Gynecol Reprod Biol 180: 100-105

91. Vafeiadi M, Vrijheid M, Fthenou E, Chalkiadaki G, Rantakokko P, et al. (2014) Persistent organic pollutants exposure during pregnancy, maternal gestational weight gain, and birth outcomes in the mother-child cohort in Crete, Greece (RHEA study). Environ Int 64: 116-123.

92. ACOG Committee Opinion No 575. (2013) Exposure to toxic environmental agents. Obstet Gynecol 122: 931-935.

93. Barker DJ, Osmond C (1986) Infant mortality, childhood nutrition, and ischaemic heart disease in England and Wales. Lancet 1: 1077-1081.

94. Berger PL, Huntington SP (2002) Many globalizations: cultural diversity in the contemporary world. Oxford University Press, New York.

95. Taubes G (2007) Good calories, bad calories. Anchor Books, New York.

96. Reid G, Nduti N, Sybesma W, Kort R, Kollmann TR, et al. (2014) Harnessing microbiome and probiotic research in sub-Saharan Africa: recommendations from an African workshop. Microbiome 2: 12.

97. Barnevik-Olsson M, Gillberg C, Fernell E (2010) Prevalence of autism in children of Somali origin living in Stockholm: brief report of an at-risk population. Dev Med Child Neurol 52: 1167-1168.

98. Enos MK, Burton JP, Dols J, Buhulata S, Changalucha J, et al. (2013) Probiotics and nutrients for the first 1000 days of life in the developing world. Benef Microbes 4: 3-16.

99. Karlsson FH, Tremaroli V, Nookaew I, Bergström G, Behre CJ, et al. (2013) Gut metagenome in European women with normal, impaired and diabetic glucose control. Nature 498: 99-103.
Citation: Chilton SN, Enos MK, Burton JP, Reid G (2015) The Effects of Diet and the Microbiome on Reproduction and Longevity: A Comparative Review Across 5 Continents. J Nutr Food Sci 5: 364. doi:10.4172/2155-9600.1000364
Submit your next manuscript and get advantages of OMICS Group submissions

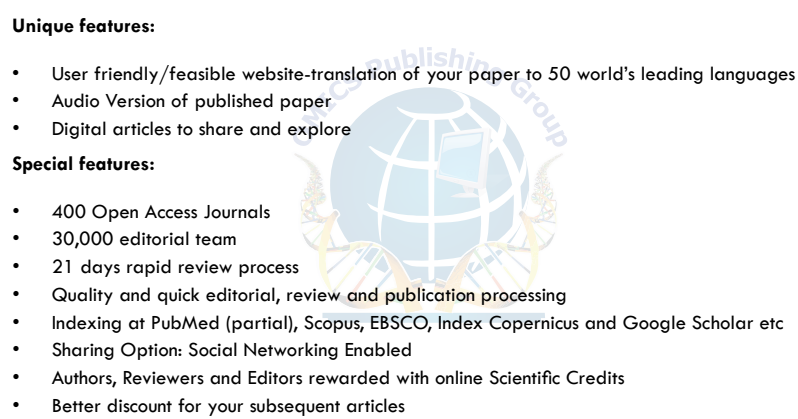

